\title{
Investigation on Fractal Characteristics of Disintegration Process and Strength of Rockfill under Water Pressure
}

\author{
Hao Cheng', Peifeng Han ${ }^{1,2,3^{*}}$, Youwen Su${ }^{1}$ \\ ${ }^{1}$ School of Civil Engineering and Architecture, Southwest University of Science and Technology, Mianyang, China \\ ${ }^{2}$ Research Center on Mountain Torrent and Geologic Disaster Prevention, Ministry of Water Resources, Wuhan, China \\ ${ }^{3}$ Shock and Vibration of Engineering Materials and Structures Key Laboratory of Sichuan Province, Mianyang, China \\ Email: ‘hanpeifeng@yeah.net
}

How to cite this paper: Cheng, H., Han, P. F., \& Su, Y. W. (2020). Investigation on Fractal Characteristics of Disintegration Process and Strength of Rockfill under Water Pressure. Journal of Geoscience and Environment Protection, 8, 20-35.

https://doi.org/10.4236/gep.2020.86003

Received: May 15, 2020

Accepted: June 15, 2020

Published: June 18, 2020

Copyright $\odot 2020$ by author(s) and Scientific Research Publishing Inc. This work is licensed under the Creative Commons Attribution International License (CC BY 4.0).

http://creativecommons.org/licenses/by/4.0/

\begin{abstract}
The paper aimed to investigate internal mechanics between disintegration of the rockfill material and stability of the dam, and further provide scientific evidence for the design of rockfills, through the conducted disintegration of water pressure and triaxial test to analyze fractal characteristics, strength and deformation of the rockfill in whole disintegration procedure. As the results that the water pressure was low $0.2 \mathrm{MPa}$, the increasing water pressure would delay the disintegration rate of rockfill; while the water pressure was above $0.2 \mathrm{MPa}$, it would promote the disintegration rate of the rockfill. In addition, in the disintegration process, the cohesion force of rockfill rapidly slowed down at the beginning and then gradually increased. The internal friction angle increased gradually during the whole disintegration process. Furthermore, when the water pressure increased from $0 \mathrm{MPa}$ to $0.6 \mathrm{MPa}$, the partial stress firstly decreased to a minimum level when the water pressure was $0.2 \mathrm{MPa}$, and then increased gradually with water pressure.
\end{abstract}

\section{Keywords}

Rockfill, Slaking Characteristics, Fractal Dimension Value, Strength, Deformation

\section{Introduction}

Materials with high strength, low compressibility and long-term stability of engineering properties are usually the first choice for damming rockfill materials. However, due to objective factors, many soft rock materials are also widely used in the filling of rockfill dams. Soft rock is usually composed of sedimentary rocks 
such as mudstone, sandy mudstone, argillaceous siltstone, argillaceous fine sandstone, argillaceous sandstone, argillaceous or sandy shale. During the long-term operation of the dam rock, the water infiltration will inevitably result in water pressure around the rockfill material. Under the action of water pressure, the rockfill material will disintegrate, which will inevitably change the particle gradation of the rockfill material, and in further change the seepage field and stress field of the rockfill. Therefore, it is necessary to study the fractal, strength and deformation characteristics of rockfill disintegration process under different real water pressure conditions.

At present, researches on soft rockfill mainly consider the particle properties and the change of strength field of rockfill under coupling actions of drying/wetting cycles or cooling/heating cycles. Wu et al., 2010 selected sandstone and mudstone for the indoor immersion disintegration test under hydrostatic pressure conditions, and analyzed the particle gradation changes of the two types of soft rock disintegration process. Wang et al., 2017 described the disintegration characteristics from three aspects: disintegration morphological change, fracture resistance index and granules. Liang et al., 2016 tested argillaceous rocks under different experimental conditions, explored the effects of drying/wetting cycles and cooling/heating cycles on the disintegration characteristics of argillaceous rocks and analyzed the disintegration ratio, porosity and water absorption of argillaceous rocks under typical climatic conditions. He et al., 2000 studied the mechanism from engineering geology, force and distance between molecular crystal packets, structural surface slip, and water properties. Yamaguchi et al., 1988 have proved that if there is no migration of water, the temperature would have almost no effect on rock disintegration. David et al., 2001 established a relationship between the disintegration of soft rock in the Triassic Basin and the uniaxial compressive strength, the liquid-plastic limit of disintegration, and the modulus through a large number of experiments. Su et al., 2005; Liu et al., 2008 studied the variation of particle size and fractal characteristics of soft rock disintegration, and pointed out that when the disintegration reaches to a certain extent, the particle size group of disintegration will remain unchanged within a certain range. In general, the present research on the disintegration of soft rock mainly focuses on the disintegration mechanism under hydrostatic pressure, while researches on soft rock disintegration underwater pressure are still scarce. Therefore, it is necessary to carry out research on the disintegration characteristics of soft rock materials under different water pressure.

The present study was based on geological field investigation, and soft rockfill materials were selected to carry out four rockfill disintegration tests under different water pressure. Based on the fractal theory, the fractal dimension of the particles in the process of rockfill disintegration was analyzed. The cohesion, internal friction angle, deviatoric stress and axial strain of the rockfill at different times during the disintegration process under different water pressure conditions were determined by triaxial test. The aim of the present study was to pro- 
vide reference for the design and construction of rockfill dams.

In the follow paragraph, we first briefly introduced that soft rock material disintegration test and fractal theory including disintegration test apparatus, procedures phenomenon and analysis of rockfill material disintegration process. In addition, we specially introduced fractal theory of rockfill and discussion particle fractal of rockfill disintegration process under different water pressure. Secondary, we briefly introduced that triaxial test procedure. Also, it is important to analyze strength and deformation of disintegrating rockfill materials. Finally, we discussed and concluded for results acquired from the above analysis data.

\section{Soft Rock Material Disintegration Test and Fractal Theory}

\subsection{Test Apparatus and Procedures}

In order to perform the water immersion disintegration test of soft rock materials under high water pressure condition, a high water pressure disintegration test system was developed by ourselves. The supercharged equipment was used to simulate the field water immersion disintegration of rockfill materials. The instrument panel, inlet and outlet water valve were used to control the pressure of the system. The test apparatus is shown in Figure 1. The soft rock used in the test was taken from a rockfill dam at a hydropower station on the upper reaches of the Minjiang River, China. The test sample is shown in Figure 2. The content of each particle size group of the test sample is shown in Figure 3. The marl samples are gray and dark gray with micrite and microcrystalline structure, the physical and mechanical parameters are shown in Table 1. The disintegration test in the present study refers to the disintegration resistance test in the rock test program (Water Resources and Hydropower Engineering Rock Testing Procedures (SL264-2001), 2001) of the Water Resources and Hydropower Engineering. In order to verify the disintegration characteristics of soft rock materials

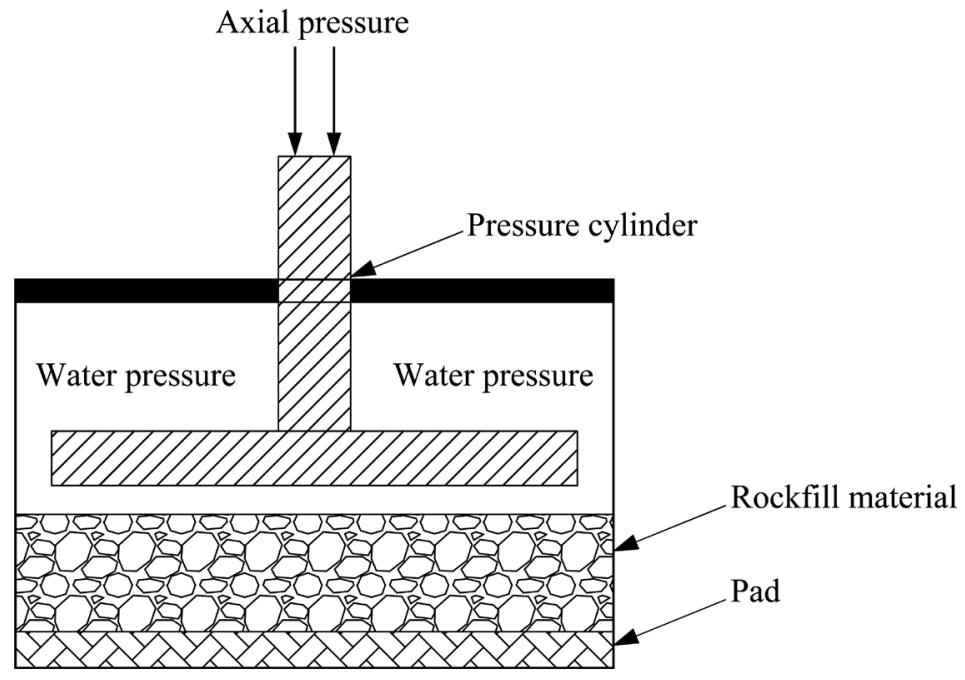

Figure 1. Schematic diagram of rockfill disintegration device. 


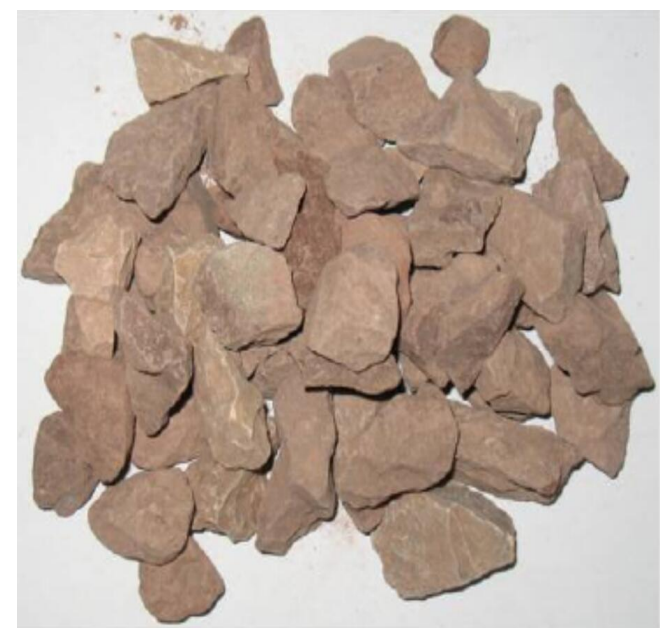

Figure 2. Soft rock sample.

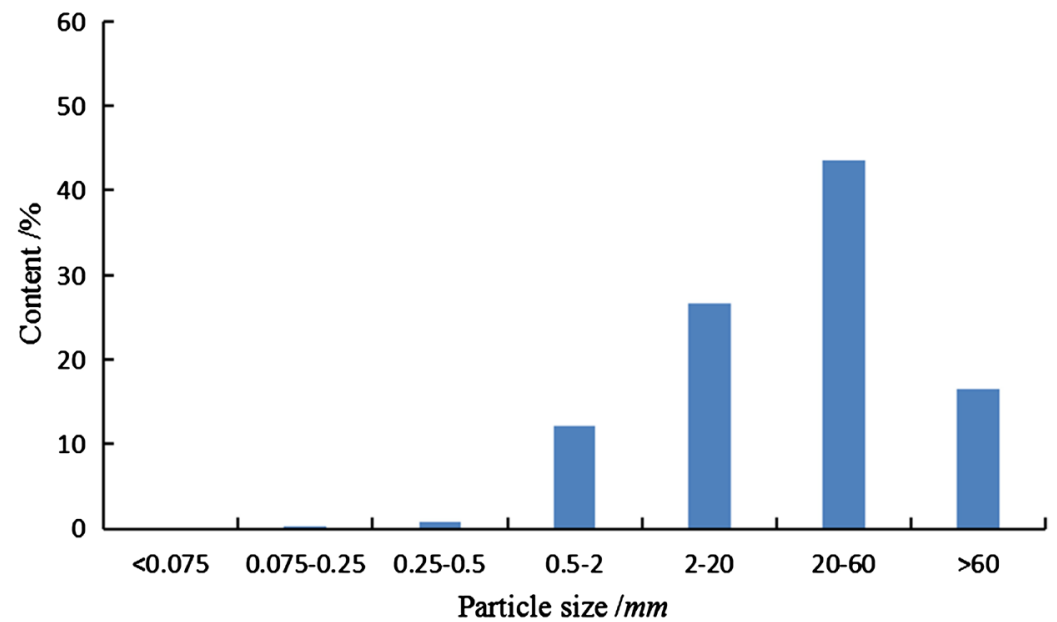

Figure 3. The content of each particle size group of the test sample.

Table 1. Basic physical and mechanical indicators of soft rock and rock materials.

\begin{tabular}{cccccc}
\hline Sample & $\begin{array}{c}\text { Natural Density } \\
\left(\mathrm{g} \cdot \mathrm{cm}^{-3}\right)\end{array}$ & $\begin{array}{c}\text { moisture content } \\
(\%)\end{array}$ & $\begin{array}{c}\text { Cohesion } \\
(\mathrm{kPa})\end{array}$ & $\begin{array}{c}\text { Internal friction } \\
\text { angle }\left(^{\circ}\right)\end{array}$ & $\begin{array}{c}\text { Softening } \\
\text { coefficient }\end{array}$ \\
\hline Soft rock & 2.33 & 3.84 & 5.79 & 36.72 & 0.72 \\
\hline
\end{tabular}

under real water pressure environment, the sampled marl rockfill materials were uniformly stirred and divided into four groups, and the axial pressure was set to $20 \mathrm{kN}$. The disintegration process under different water pressure was simulated according to the water depth of the rockfill materials. The water pressure is 0 $\mathrm{MPa}$ (conventional water immersion test, ignoring water pressure), $0.2 \mathrm{MPa}, 0.4$ $\mathrm{MPa}$, and 0.6 $\mathrm{MPa}$. The selected soft rock sample was immersed in high pressure water, and the disintegration processes were carefully observed and recorded. After the disintegration, the disintegrated materials were dried, and the variation rule of disintegration gradation was analyzed (Cao et al., 2006; Deng et al., 2014). During the disintegration process, samples were taken every six hours and were air-dried for screening test. 


\subsection{Disintegration Test Phenomenon and Analysis of Rockfill Material Disintegration Process}

In the disintegration test, cracking occurred firstly, and then some large pieces dropped, afterwards the pointed end of the dropped large pieces slowly turned to round and decomposed into small particles similar to ellipsoid. In order to analyze the variation characteristics of the particle size of rockfill materials during the disintegration process, each group of rockfill material was disintegrated for 6 $h$, then was taken out to dry and sieve. Based on the fractal theory, the tests of resistant to disintegration under four different water pressure conditions were carried out. The change rules of the particle size of the rockfill material the 0 $h-72 \mathrm{~h}$ process were analyzed, and then the variation of the particle size of the rockfill material at different disintegration time under different water pressure conditions in the rockfill disintegration test was obtained, which is shown in Figure 4 .

As can be seen from Figure 4, the disintegration rates of different particle sizes of rockfill materials were different even under the same water pressure. As the development of the disintegration, particles smaller than $2 \mathrm{~mm}$ continuously increased, and particles larger than $20 \mathrm{~mm}$ continuously decreased, in the meanwhile, particles with $2-20 \mathrm{~mm}$ in diameter increased firstly and then gradually decreased. This indicates that the coarse-grained rockfill particles firstly disintegrate into medium-sized particles, and these medium-sized rockfill particles

(a)

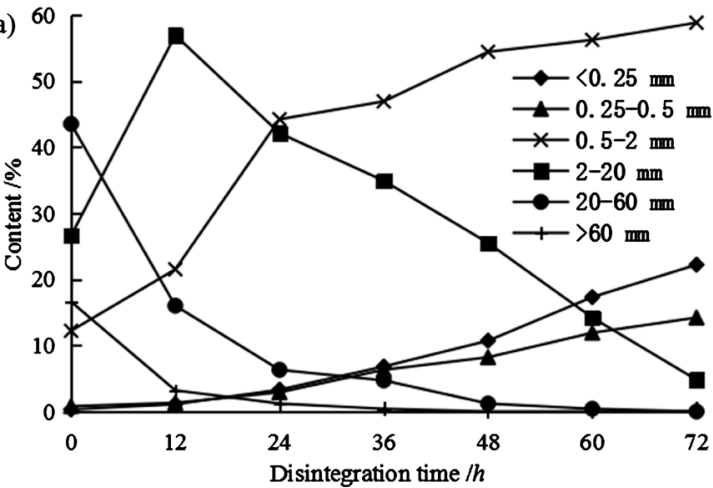

(c)

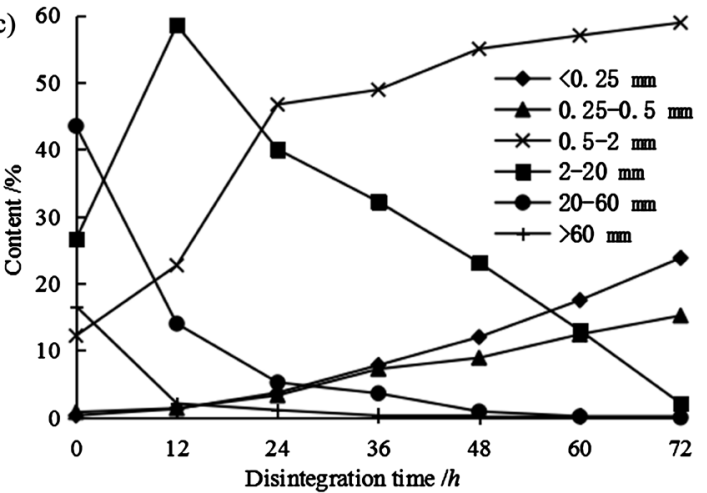

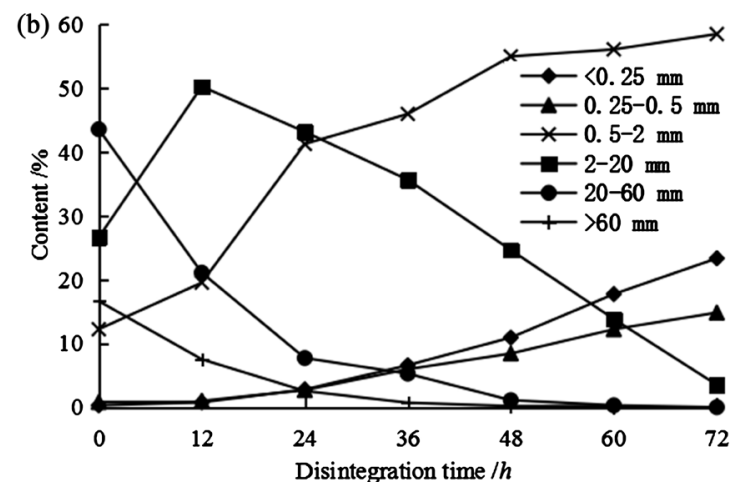

(d)

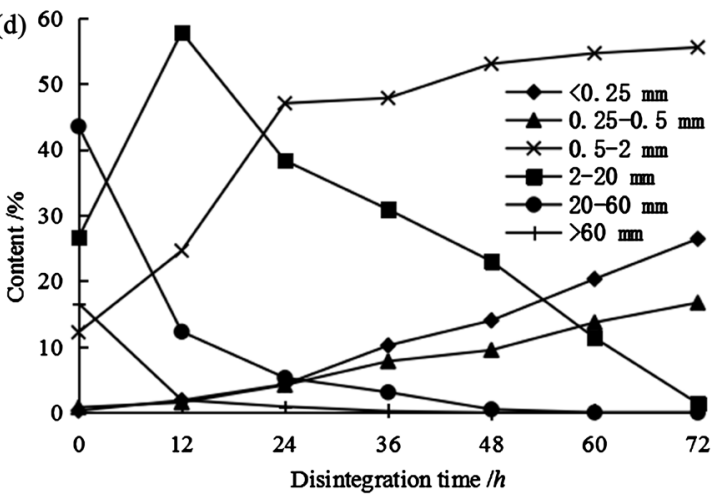

Figure 4. Variation of particle size group content of rockfill materials under four water pressures. (a) $0 \mathrm{MPa}$; (b) $0.2 \mathrm{MPa}$; (c) $0.4 \mathrm{MPa}$; (d) $0.6 \mathrm{MPa}$. 
gradually disintegrate into fine particles as the soaking time prolonged. Different water pressure has significant effect on the disintegration characteristics of soft rock. It is found from Figure 4 that the disintegration rate of soft rock begins to decrease with the water pressure increased, and the disintegration rate is lowest when the water pressure is $0.2 \mathrm{MPa}$. Then the disintegration rate increased with the water pressure increasing, indicating that the water pressure has a retarding effect on the disintegration of rockfill when the water pressure is low. When the water pressure continues to increase, high water pressure will increase the disintegration rate of the soft rockfill.

We also analyzed the effect of water pressure on the disintegration rate of soft rockfill materials. Figure 5 shows the percentage of different particle size groups of soft rockfill materials at different times under four different water pressure conditions.

In the present study, the initial content ratio of particles with different size was the same. Under different water pressure, the content ratio of particles with different particle size began to change, and the changes showed different trends. When the disintegration time is the same, with the increase of water pressure, particles smaller than $0.5 \mathrm{~mm}$ continues to increase; while particles greater than $0.5 \mathrm{~mm}$ increase gradually after disintegration for $24 \mathrm{~h}$, as the prolongation of disintegration time, its content began to show a trend of increasing firstly and then decreasing, but the rate of increasing and decreasing was not completely
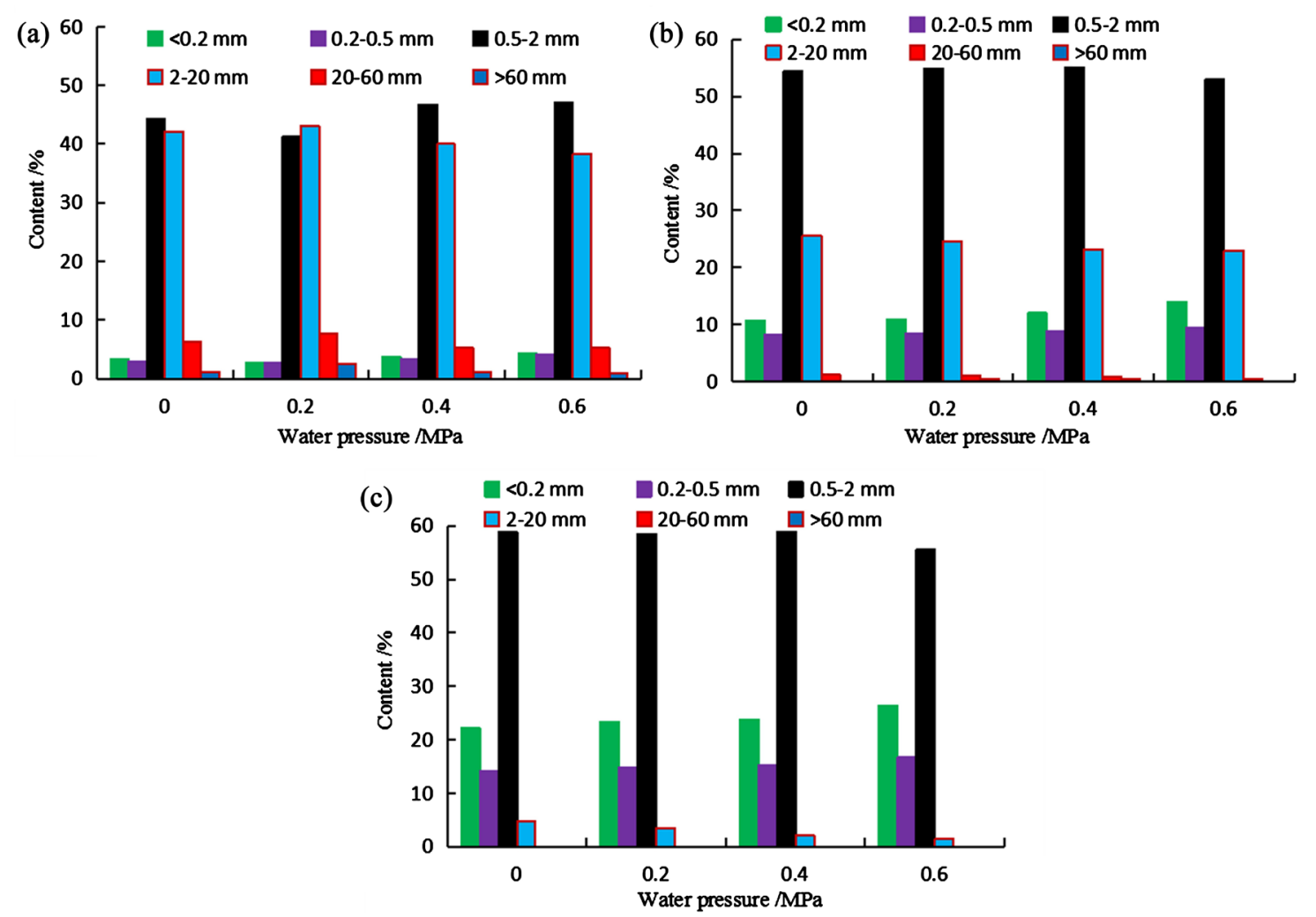

Figure 5. Variation diagram of particle sizegroup at different disintegration times of rockfill under four water pressures. (a) $24 \mathrm{~h}$; (b) $48 \mathrm{~h}$; (c) $72 \mathrm{~h}$. 
consistent. The reason for this phenomenon is mainly that particles with large size disintegrate into fine particles, so that the fine particles smaller than $0.5 \mathrm{~mm}$ is increased, while the content of particles with large size group is dynamically changing. At the $24 \mathrm{~h}$ of disintegration, as the water pressure increases, the ratio of the $0.5-2 \mathrm{~mm}$ particles continues to increase, indicating that the large particles disintegrate into $0.5-2 \mathrm{~mm}$ particles at a rate greater than the disintegration of the $0.5-2 \mathrm{~mm}$ particles. The ratio of $2-60 \mathrm{~mm}$ particles increases firstly and then decreases gradually. When the disintegration time continues to increase to $48 \mathrm{~h}$, the particles greater than $2 \mathrm{~mm}$ decrease as the water pressure increases. The reason for this phenomenon is that particles of large size disintegrate into particles of small size during the disintegration process, and particles of small size disintegrate into particles of smaller size, and the ratio of particles with middle size remains in a dynamic equilibrium changing. When the disintegration rate of particles with middle size is greater than that of other groups with different particle size, the ratio of middle-size particles decreases, and vice versa.

\subsection{Fractal Theory of Rockfill}

Fractal geometry is used to describe the random and chaotic phenomena and behaviors. At present, most of the linear fractal theory is used to describe the random phenomena and behaviors, named the self-similarity fractal theory ( $\mathrm{He}$ et al., 2014). Ozkan \& Ortoleva, 2000 considered that particle fragmentation is a Markov process. Based on this, a Markov fractal model was established, which can be used to describe the evolution law of gradation. Mandelbrot \& Wheeler, 1983 proposed a fractal theory to establish a two-dimensional spatial fractal dimension model of particle size. Tyler \& Wheatcraft, 1992 proposed a normalized equation of mass and pore size relationship, established a weight distribution model of the fractal dimension of soil particle size distribution, and sieved particles with a pore size. The total number of particles passing through the sieve was counted as $M_{1}(r)$, the total number of remaining rockfills is calculated as $M_{2}(r)$, and the total amount of samples is $M_{t}$.

$$
M_{t}=M_{1}(r)+M_{2}(r)
$$

Based on the three-dimensional fractal model, it is assumed that the density of soft rock with different particle sizes is the same. The mass instead of the volume of the rockfill particles is used to construct the distribution model of the fractal dimension of the particle size distribution of the rockfill.

In the three-dimensional structure of soft rock, the volume of the rockfill material larger than the particle size $d_{i}$ is $V$, then there is:

$$
V\left(r>d_{i}\right)=C_{v}\left[1-\left(d_{i} / \lambda_{v}\right)^{3-D}\right]
$$

In the above formula, $r$ is the particle size of the rockfill material, $D$ is the fractal dimension; $C_{V}$ is the uneven coefficient of the rockfill; $\lambda_{V}$ is the constant related to the particle size. According to Tyler's assumption, particles with different particle sizes have the same density, so the quality of a certain particle size 
is:

$$
M_{2}\left(r>d_{i}\right)=\rho V(r>d)=\rho C_{v}\left[1-\left(d_{i} / \lambda_{v}\right)^{3-D}\right]
$$

In the formula: $\rho$ is the density of rockfill material, $d_{i}$ is a kind of particles that with a certain diameter. Let $d_{i}=0$, then $M_{2}\left(d_{i}\right)$ in Equation (3) is the total mass of all rockfill materials, nameed $M_{\mathrm{t}}$ and:

$$
M_{t}=\rho C_{v}
$$

If it is assumed that the maximum diameter of the soft rockfill sample is $d_{\max }$, then $M_{2}\left(d_{\max }\right)=0$, substituting it into Equation (3), we can come to the following conclusion:

$$
\lambda_{v}=d_{\max }
$$

From the Formulas (2)-(5), the fractal relationship between the mass of the soft rock and the particle size is:

$$
\frac{M_{1}\left(d_{i}\right)}{M_{t}}=\frac{1-M_{2}\left(d_{i}\right)}{M_{t}}=\left(\frac{d_{i}}{d_{\max }}\right)^{3-D}
$$

Taking the logarithm of both sides of Equation (6), we can come to the following conclusion:

$$
\lg \left[M_{1}\left(d_{i}\right) / M_{t}\right]=(3-D) \times \lg \left(d_{i} / d_{\max }\right)
$$

In the above fomular, $M_{1}\left(d_{i}\right) / M_{t}$ can be caculated by sieving test, and the slope $\mathrm{k}$ could be obtained according to the linear equation of $D=3-\mathrm{k}$, then we could calculate the fractal dimension $D$ of the rockfill.

\subsection{Particle Fractal of Rockfill Disintegration Process under Different Water Pressure}

Based on the fractal model, the fractal dimension values of particle decomposition of soft rockfill materials at different times during disintegration were analyzed under four different water pressure conditions. The fractal dimension calculation results are shown in Figure 6.

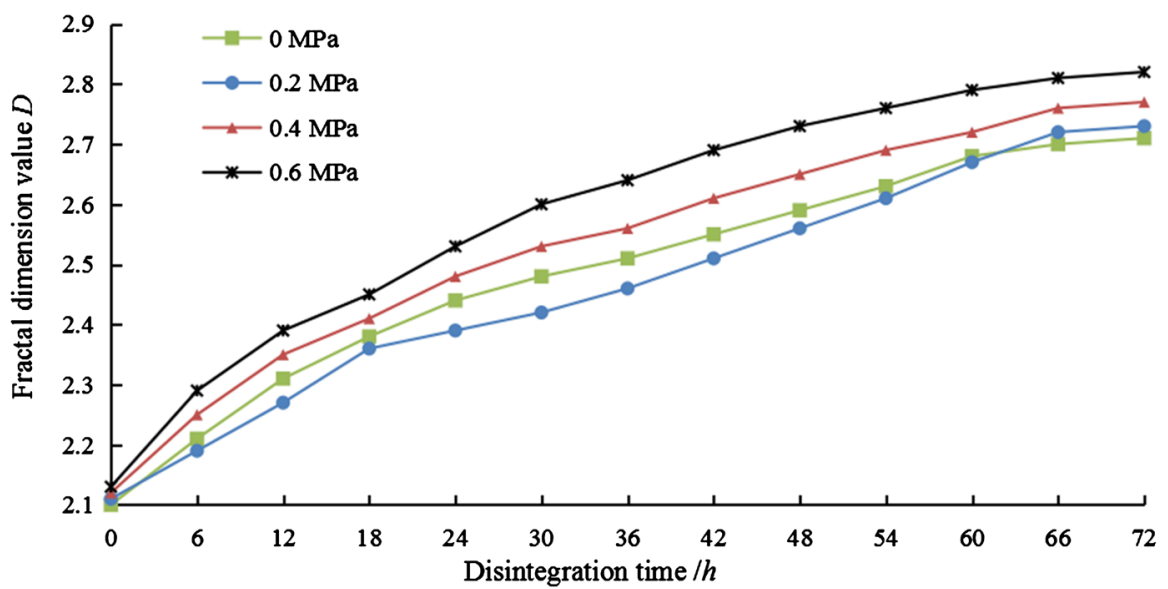

Figure 6. Variation of fractal dimension of rockfill during disintegration under different water pressure. 
The disintegration characteristics of soft rockfill materials during disintegration under different water pressure are different. It can be seen from Figure 6 that with the extension of disintegration time, the fractal dimension of rockfill materials began to grow rapidly and then grow slowly. The rate was slowed down until the stable state was reached. When the water pressure was $0.2 \mathrm{MPa}$, the fractal dimension of the rockfill is less than that of the water pressure was 0 $\mathrm{MPa}$. When the water pressure was greater than $0.2 \mathrm{MPa}$, the fractal dimension of the rockfill increased as the increase of the water pressure. It indicates that when the water pressure is low, the water pressure has an inhibitory effect on the disintegration rate of the rockfill. When the water pressure increases to a certain extent, the water pressure will promote the disintegration rate of the rockfill.

\section{Triaxial Test and Results Analysis of Disintegrating Rockfill Materials}

\subsection{Test Procedure}

In order to study the effect of rockfill disintegration characteristics on the strength and deformation of rockfill under different water pressure, we adopted a microcomputer-controlled electro-hydraulic servo static triaxial tester, and test material was scaled according to the specification and other mass substitution methods. In addition, the sample was divided into 4 equal parts, and was loaded in 4 layers while compacted, compacting height (Jiang et al., 2016; Chen et al., 2015) of each sample was strictly controlled by ruler measurement. During the process of loading the shear rate was set at $0.5 \mathrm{~mm} / \mathrm{min}$, and the large-scale triaxial consolidation drainage shear test was carried out under the confining pressures of $100 \mathrm{kPa}, 200 \mathrm{kPa}, 400 \mathrm{kPa}$ and $700 \mathrm{kPa}$, respectively, so as to meet the sufficient discharge and pores. Also, test process and requirements are strictly in accordance with the Geotechnical Test Procedure for Water Resources and Hydropower Engineering (Water Resources and Hydropower Engineering Rock Testing Procedures (SL264-2001), 2001).

\subsection{Analysis of the Strength of Disintegrated Rockfill}

The cohesive force and internal friction angle of rockfill materials under different water pressure conditions were measured at different times. Based on the fractal theory proposed by Mandelbrot, the fractal dimension and cohesion force curves of soft rockfill materials under different water pressure conditions at different times were obtained (Figure 7). In addition, the relationship of the fractal dimension and cohesion during the disintegration of the rockfill is shown in Figure 8.

Through the triaxial test, the cohesive force of the disintegrating rockfill under different water pressures is shown in Figure 7. As can be seen from Figure 7, when the disintegration time was prolonged, the cohesive force of the rockfill material began to decrease rapidly and then decrease slowly. When the cohesive force reduced to a certain extent, it began to increase slowly. The main reason is 

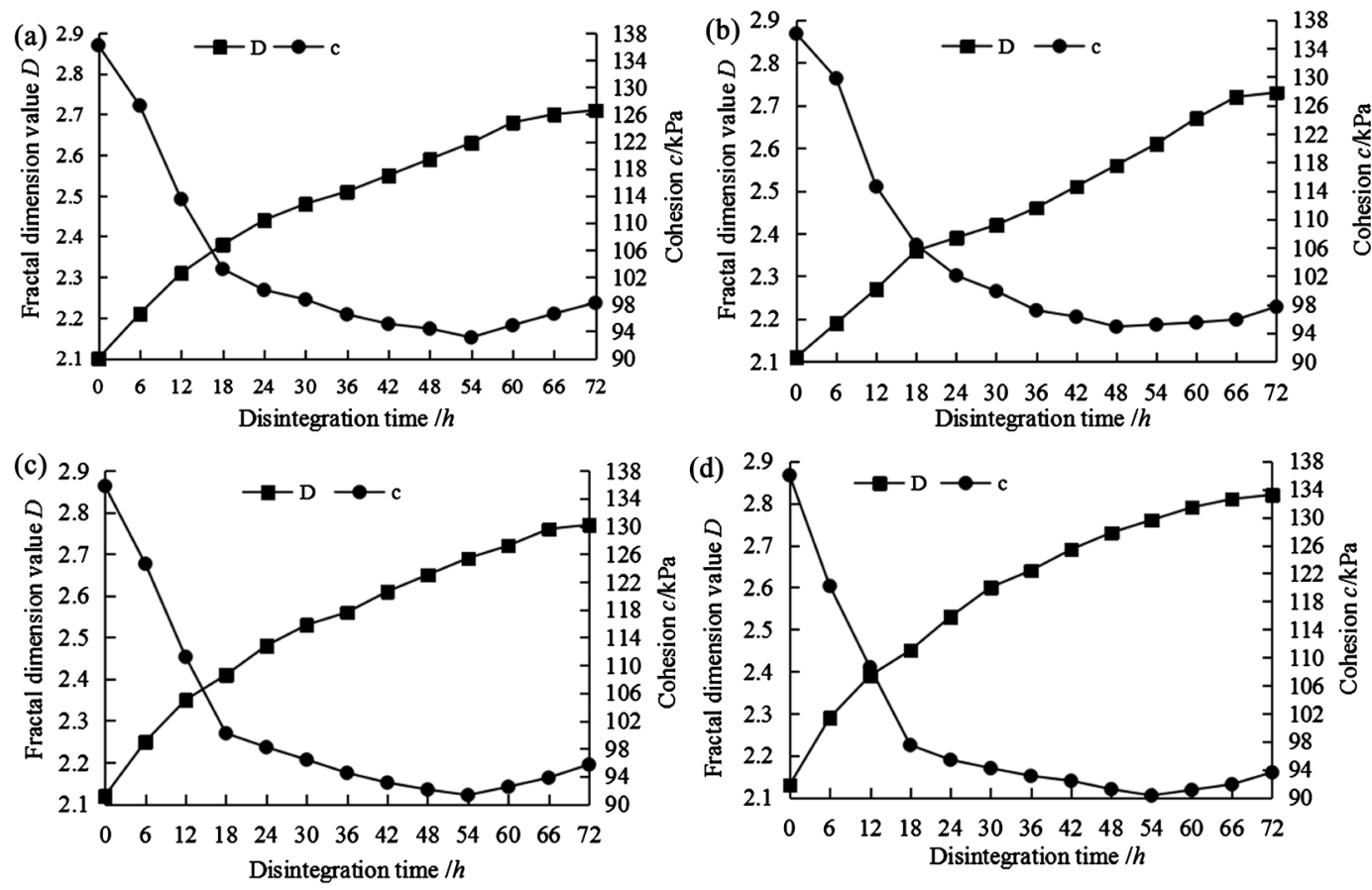

Figure 7. Variation of fractal dimension and cohesion of rockfill materials with time under different water pressures. (a) $0 \mathrm{MPa}$; (b) $0.2 \mathrm{MPa}$; (c) $0.4 \mathrm{MPa}$; (d) $0.6 \mathrm{MPa}$.

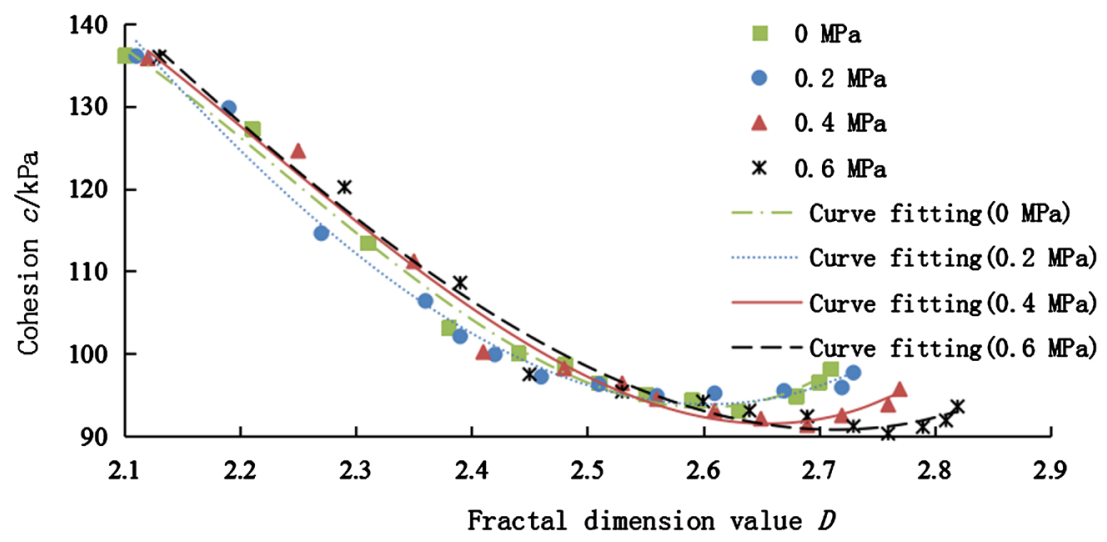

Figure 8. Relationship diagram of fractal dimension and cohesion under different water pressure.

that the coarse-grained rockfill decomposed and cracked, which resulted in lower cohesive force. In addition, some of the pressurized water penetrating into the joints and cracks of coarse particles caused a decrease in cohesive force. As the disintegration time prolonged, the fractal dimension of the rockfill began to grow rapidly, while the growth rate slowed down in the later stage. From Figure 8, we can see there is correlation between the fractal dimension and the cohesion. As the fractal dimension of the rockfill increased during the disintegration process, the cohesive force of the rockfill decreased rapidly to a minimum level, and then began to increase slowly. Fitting the scatter plot of the fractal dimension and cohesion force under four different water pressure as $0 \mathrm{MPa}, 0.2 \mathrm{MPa}$, $0.4 \mathrm{MPa}$ and $0.6 \mathrm{MPa}$, it was found that the change of fractal dimension and co- 
hesion was satisfied with the cubic polynomial, $y=a x^{3}-b x^{2}+c x-d$, where $a$, $b, c, d$ is a constant. The corresponding $R^{2}$ is $0.9884,0.9827,0.9839$, and 0.9912 , respectively.

The relationship between fractal dimension and internal friction angle of disintegration time during disintegration of soft rockfill under four types of water pressure is shown in Figure 9. As can be seen from Figure 9, as the disintegration time is prolonged, the internal friction angle of the rockfill material increased faster in the beginning and slower in the later stage. The internal friction angle begins to grow at a faster rate, and then becomes slower. At the initial stage of disintegration, some of the coarse-grained rockfill material disintegrated into fine particles to fill the gap of the coarse particles, so that the internal friction angle of the rockfill material increased rapidly. As the coarse particles continued to disintegrate into fine particles, the increase of the internal friction angle slowed down. It can be seen from the four graphs that under the four conditions of water pressure of $0 \mathrm{MPa}, 0.2 \mathrm{MPa}, 0.4 \mathrm{MPa}, 0.6 \mathrm{MPa}$, the internal friction angle of the rockfill is the smallest when the water pressure is $0.2 \mathrm{MPa}$. When the water pressure increased from 0.2 $\mathrm{MPa}$, the internal friction angle increased accordingly. It is indicated that the water pressure can increase the internal friction angle of the rockfill material when the water pressure is low, thereby increasing the strength of the rockfill material. When the water pressure continues to increase (greater than 0.2 $\mathrm{MPa}$ ), the internal friction angle of the rockfill material began to decrease, and the strength of the rockfill material was lowered.

Based on the relationship between the internal friction angle and the fractal dimension, a scattergram of the fractal dimension and the internal friction angle
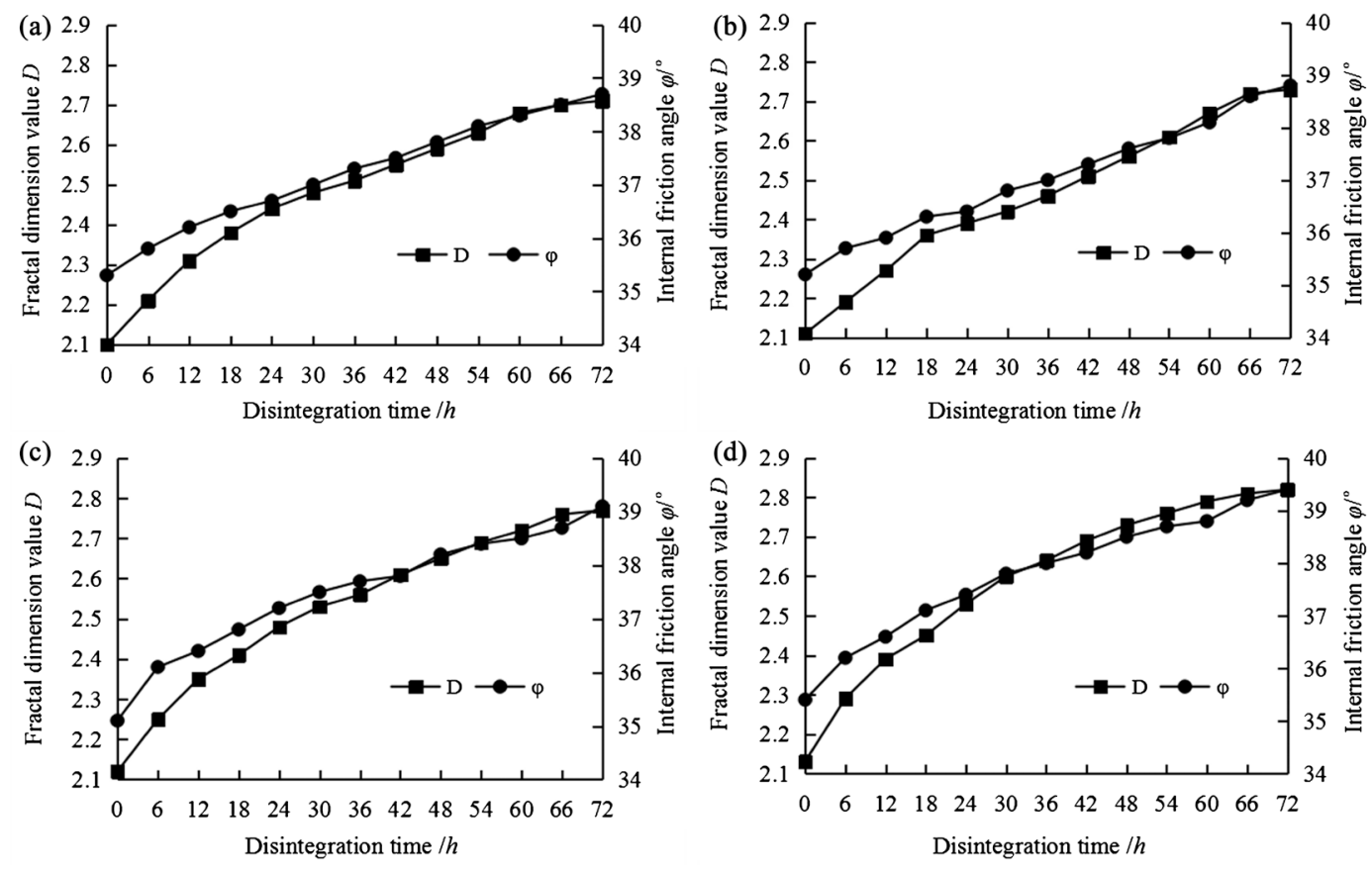

Figure 9. Variation of fractal dimension and internal friction angle of rockfill with time under different water pressures. (a) $0 \mathrm{MPa}$; (b) $0.2 \mathrm{MPa}$; (c) $0.4 \mathrm{MPa}$; (d) $0.6 \mathrm{MPa}$. 
was obtained (Figure 10). It can be seen that when the fractal dimension continued to increase, the internal friction angle of the rockfill began to increase rapidly in the beginning, then the acceleration became smaller, however, it increased rapidly again in the later stage. Fitting the scatter plots of fractal dimension and internal friction angle under four types of water pressure of $0 \mathrm{MPa}, 0.2$ $\mathrm{MPa}, 0.4 \mathrm{MPa}$ and $0.6 \mathrm{MPa}$, the relationship of fractal dimension and internal friction angle of rockfill during the disintegration process is satisfied with the cubic polynomial, $y=a x^{3}-b x^{2}+c x-d$, where $a, b, c$, and $d$ are constants. The corresponding $R^{2}$ is $0.9856,0.9872,0.9904$ and 0.9869 , respectively.

\subsection{Deformation Analysis of Rockfill}

In order to analyze the relationship between deviatoric stress and the axial strain of disintegrated fragmentation during the triaxial test, the large-scale triaxial consolidation drainage shear test was performed at the disintegration time of 0 $\mathrm{h}, 24 \mathrm{~h}, 48 \mathrm{~h}$ and $72 \mathrm{~h}$. These tests were under the confining water pressures of $100 \mathrm{kPa}, 200 \mathrm{kPa}, 400 \mathrm{kPa}$ and $700 \mathrm{kPa}$. The results are shown in Figure 11.

As can be seen from Figure 11, as the disintegration time of the rockfill prolonged, the corresponding axial strain of certain deviatoric stress became smaller and smaller. In the initial stage, the deviatoric stress increased rapidly as the increase of axial strain, and begins to decrease slowly when it reached a maximum level. As the development of the disintegration, the coarse-grained rockfill material was decomposed into fine particles to fill the voids of the rockfill material, which resulted in decrease of the strength and the deviatory stress of the rockfill. When the axial strain keeps the same, the deviatory stress was positively associated with the confining pressure of the triaxial test.

In order to analyze the influence of water pressure on deviatoric stress and axial strain of rockfill, the disintegrated fragmentation at $12 \mathrm{~h}, 24 \mathrm{~h}, 36 \mathrm{~h}$ and 48 $\mathrm{h}$ were selected and subjected to triaxial test (confining pressure was $400 \mathrm{kPa}$ ). The relationship curve of the water pressure, deviatoric stress and axial strain is shown in Figure 12.

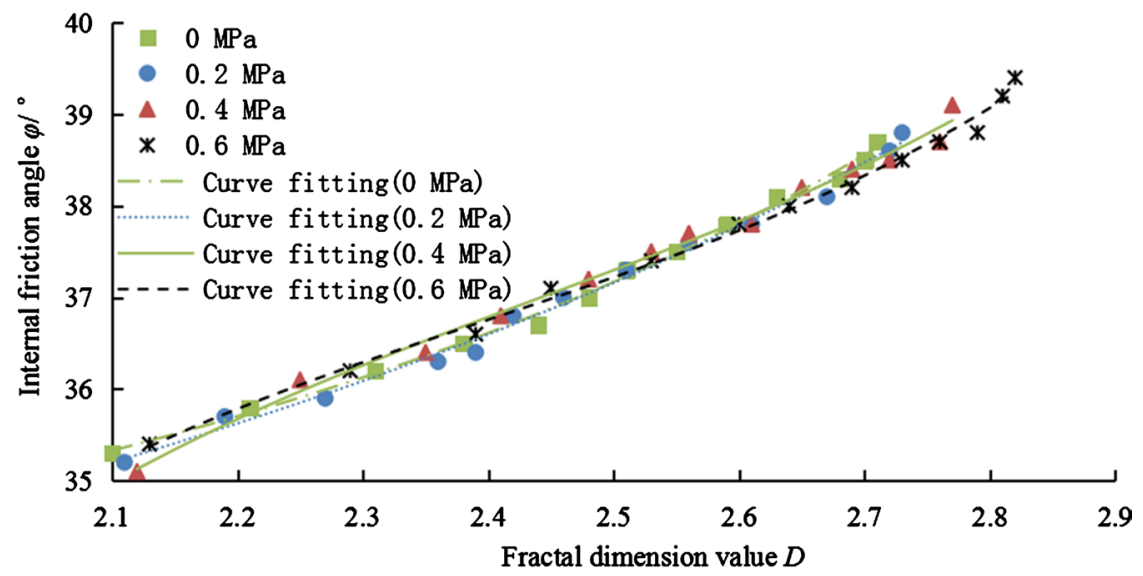

Figure 10. Curve diagram of fractal dimension and internal friction angle of rockfill under different water pressures. 

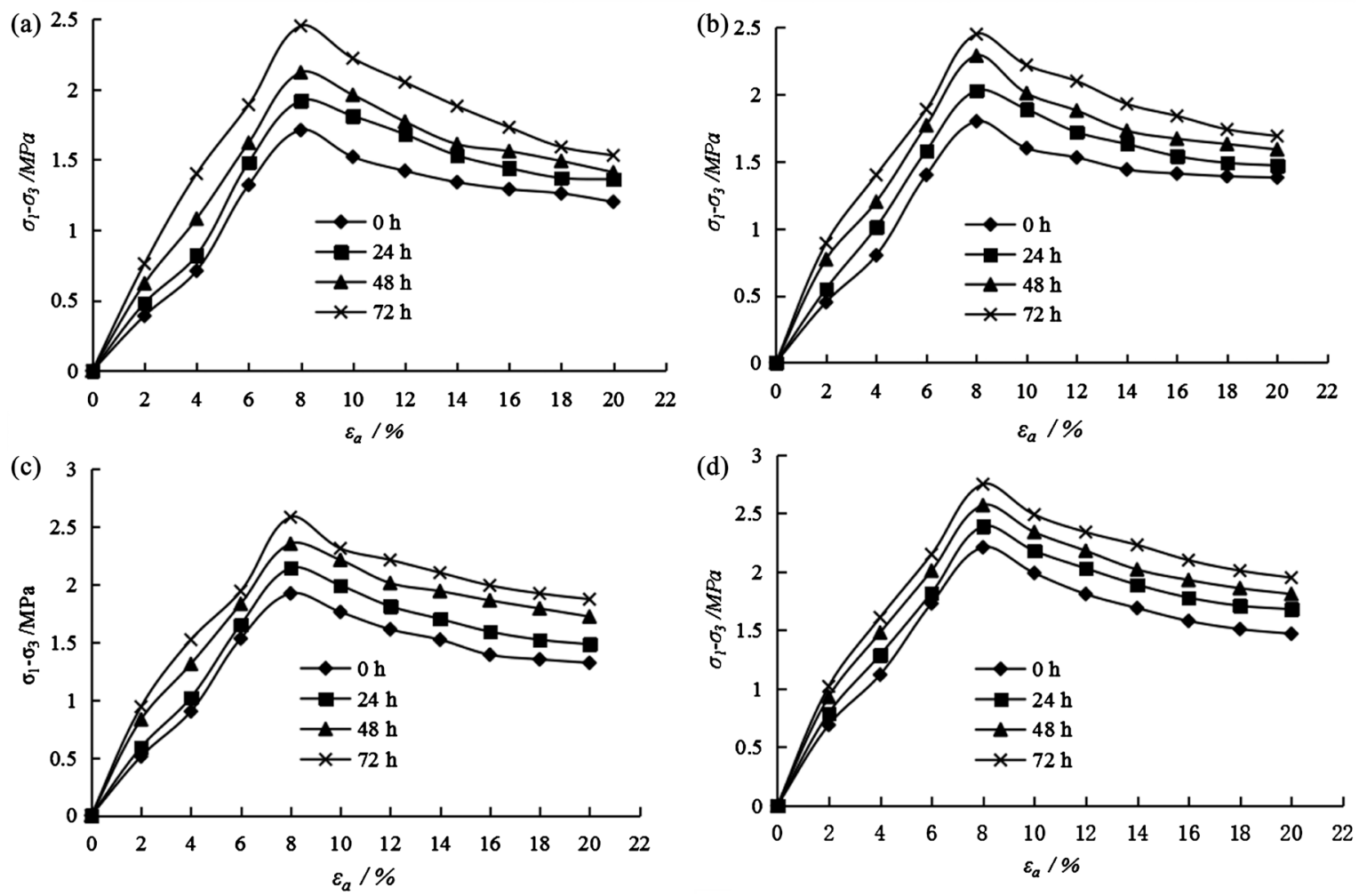

Figure 11. Deviation stress-axial strain curve of rockfill under different confining pressures. (a) $100 \mathrm{kPa}$; (b) $200 \mathrm{kPa}$; (c) $400 \mathrm{kPa}$; (d) $700 \mathrm{kPa}$.
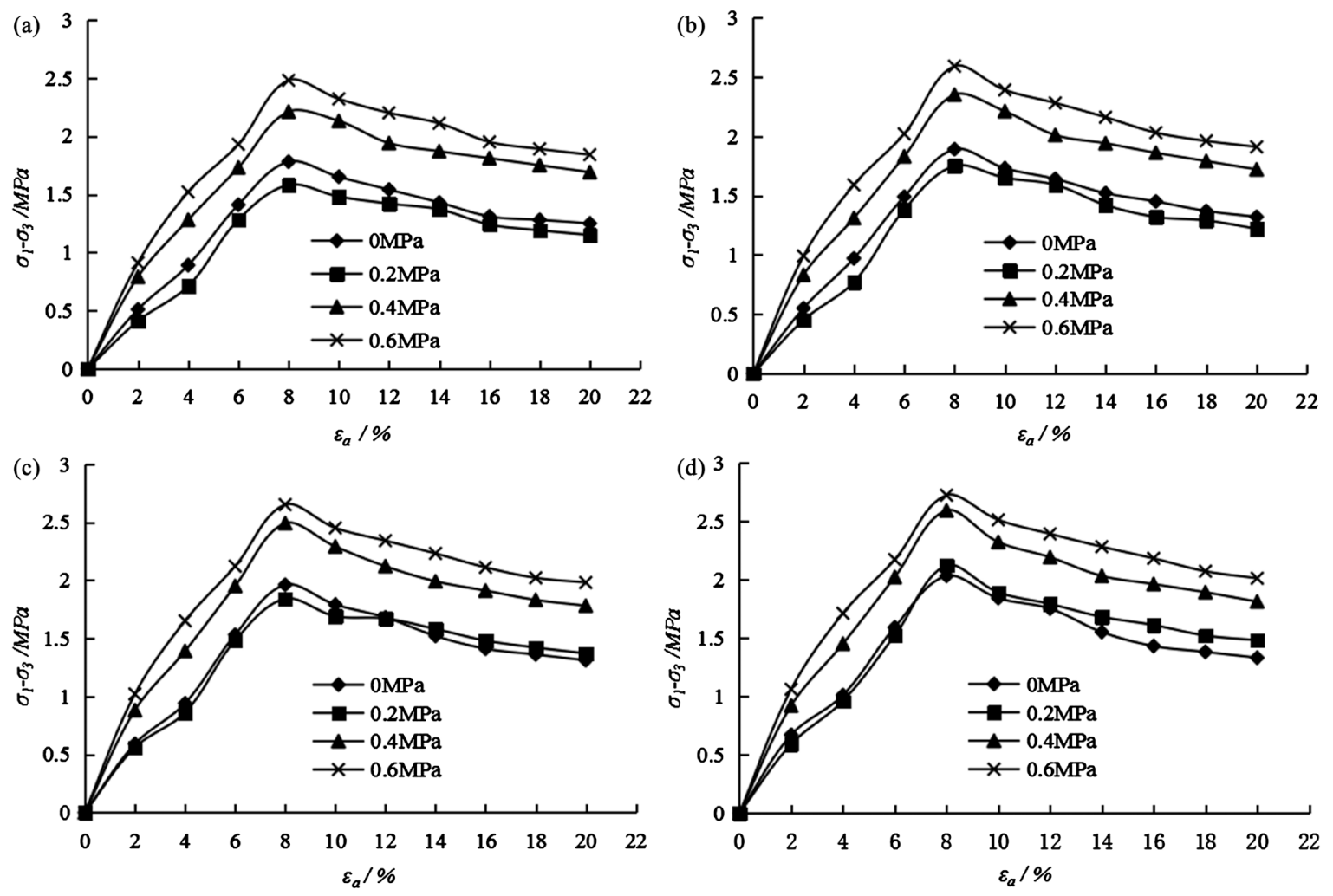

Figure 12. Deviatoric stress-axial strain curve of rockfill under different disintegration time. (a) 12 h; (b) 24 h; (c) 36 h; (d) $48 \mathrm{~h}$. 
It can be seen from Figure 12 that the stress and strain of the rockfill are different when subjected to different water pressure. When the water pressure increased from $0 \mathrm{MPa}$ to $0.6 \mathrm{MPa}$, the corresponding deviatoric stress of the same axial strain decreased firstly to the minimum level when the water peressure was $0.2 \mathrm{MPa}$; and then the deviatoric stress became to increase gradually as the increase of axial strain. The main reason of this phenomenon is mainly because the low water pressure can delay the disintegration rate of the rockfill. The longer the time for the rockfill disintegration, the greater the deviatoric stress-axial strain of the rockfill material, which is not good for the stabilization of the rockfill dam.

\section{Conclusion}

Based on fractal theory, particle characteristics of soft rockfill disintegration under different water pressure were analyzed in the present study. The changing rules of the cohesive force, internal friction angle and deviatoric stress-axial strain of the rockfill during the disintegration process were investigated by triaxial test. The main conclusions are as follows:

1) Water pressure has a significant effect on the disintegration characteristics of soft rock. When the water pressure rises from $0 \mathrm{MPa}$ to $0.2 \mathrm{MPa}$, the disintegration rate of soft rockfill material decreases gradually to a minimum level; it implies that when the water pressure is low, the water pressure has an inhibitory effect on the disintegration rate of the rockfill. When the water pressure is higher than $0.2 \mathrm{MPa}$, the rate of disintegration of the rockfill begins to increase as the water pressure increases. It indicates that lower water pressure delays the disintegration of the rockfill material, while higher water pressure promotes the disintegration.

2) The fractal dimension of rockfill material increases rapidly at the beginning of the disintegration, and then increases slowly to a stable state. When the water pressure rises from $0 \mathrm{MPa}$ to $0.6 \mathrm{MPa}$, the fractal dimension of the rockfill material begins to decrease slowly to a minimum level; when the water peressure was $0.2 \mathrm{MPa}$, the fractal dimension begins to increase gradually as the increase of water pressure.

3) As the time of disintegration prolonged, the cohesive force of the rockfill material decreases rapidly in the beginning and then gradually decreases to a certain extent, after that it gradually increases. The internal friction angle of the rockfill material increases rapidly in the initial stage and decreases slowly in the later stage. The rate of growth is faster and then slower and slower. Fitting the fractal dimension-the cohesion scatter plot and the fractal dimension-internal friction angular scatter plot under four different water pressure of $0 \mathrm{MPa}, 0.2 \mathrm{MPa}, 0.4$ $\mathrm{MPa}, 0.6 \mathrm{MPa}$, it was found that the fractal dimension, cohesion force and internal friction angle are all satisfied with the polynomial: $y=a x^{3}-b x^{2}+c x-d$, where $a, b, c, d$ is constant.

4) As the time of disintegration prolonged, the corresponding axial strain of 
certain deviatoric stress became smaller and smaller. In the meanwhile, the deviatoric stress increased rapidly as the increase of axial strain; when the strain continues to increase, the deviatory stress begins to decrease slowly. The deviatory stress-axial strain of soft rockfill under different water pressure disintegration is different. When the water pressure is increased from $0 \mathrm{MPa}$ to $0.6 \mathrm{MPa}$, the corresponding deviatoric stress of same axial strain begins to decrease slowly to a minimum level; when the water peressure was $0.2 \mathrm{MPa}$, the deviatoric stress begins to increase gradually as the increase of water pressure.

5) In the discrete element simulation static penetration test, generating particles with increasing particle size to the boundary based on meso-structure, and then optimizing parameters according to the particle size relationship scale, could improve the simulation effect.

\section{Acknowledgements}

This work was supported by the Postgraduate Innovation Fund Project by Southwest University of Science and Technology, China (Grant No. 19ycx0087), and the Research Center on Mountain Torrent and Geologic Disaster Prevention Foundation, Ministry of Water Resources, China (Grant No. CKWV2019759/KY).

\section{Conflicts of Interest}

The authors declare no conflicts of interest regarding the publication of this paper.

\section{References}

Cao, Y. J., Huang, R. Q., \& Zheng, H. J. (2006). Slakig Characteristics of Soft Rock of the Engineering Slope in a Hydroelectric Station in the Southwest of China. Journal of Engineering Geology, 14, 35-40.

Chen, Y., Ma, D. T., \& He, D. W. (2015). Tests for Sandstone Strength and Failure Model under Water Loading. Journal of Sichuan University: Engineering Science Edition, 47, 59-64.

David, W. P. (2001). Slake Durability and Engineering Properties of Durham Triassic Basin Rock (pp. 85-96). Raleigh, NC: North Carolina State University.

Deng, T., Huang, M., \& Zhan, J. W. (2014). Fractal Evolution Law of Clay Rock Disintegration Under Different pH Conditions. Journal of Tongji University (Nature Science), 42, 1480-1485.

He, M. C., Jing, H. H., \& Sun, X. M. (2000). Research Progress of Soft Rock Engineering Geomechanics in China Coal Mine. Journal of Engineering Geology, 8, 46-62.

He, N., Chen, N. S., Zhu, Y. H. et al. (2014). Experiment Study of Fractal Feature and Relationship between Fractal Dimension and Permeability Coefficient of Gravelly Soil in Debris Flow Source Area. Rock and Soil Mechanics, 35, 2543-2548.

Jiang, Y., Liu, C. W., Xie, H. et al. (2016). Study on Triaxial Creep Characteristics of High-water-material Under Real Water Environment. Journal of Sichuan University: Engineering Science Edition, 48, 87-93.

Liang, B., Tan, X. Y., Jiang, L. G. et al. (2016). Effects of Freeze-thaw and Drying-wetting Cycles on Slaking Characteristics of Mudstone. Chinese Journal of Geotechnical Engi- 
neering, 38, 705-711.

Liu, X. M., Zhao, M. H., \& Su, Y. H. (2008). Mathematical Simulation of Fractal Mechanism for Slaking of Soft Rock. Rock and Soil Mechanics, 2, 2043-2047.

Mandelbrot, B. B., \& Wheeler, J. A. (1983). The Fractal Geometry of Nature. American Journal of Physics, 51, 286. https://doi.org/10.1119/1.13295

Ozkan, G., \& Ortoleva, P. J. (2000). Evolution of the Gouge Particle Size Distribution: A Markov Model. Pure and Applied Geophysics, 157, 449-468. https://doi.org/10.1007/s000240050008

Su, Y. H., Zhao, M. H., \& Liu, X. M. (2005). Research of Fractal Mechanism for Swelling \& Collapse of Soft Rock. Rock and Soil Mechanics, 26, 728-732.

The People's Republic of China (2001). Water Resources and Hydropower Engineering Rock Testing Procedures (SL264-2001) (pp. 20-22). Beijing: China Water Conservancy and Hydropower Press.

Tyler, S. W., \& Wheatcraft, S. W. (1992). Fractal Scaling of Soil Particle Size Distributions: Analysis and Limitations. Soil Science Society of America Journal, 56, 362-369. https://doi.org/10.2136/sssaj1992.03615995005600020005x

Wang, L., Deng, H., Deng, T. H. et al. (2017). Correlation between Disintegration Resistance and Particle Size of Mudstone. Journal of Yangtze River Scientific Research Institute, 34, 120-124.

Wu, D. X., Liu, H. J., \& Wang, G. Q. (2010). Laboratory Experimental Study of Slaking Characteristics of Red-Bed Soft Rock. Chinese Journal of Rock Mechanics and Engineering, 29, 4173-4179.

Yamaguchi, H., Yoshida, Y., Kuroshima, I. et al. (1988). Slaking and Shear Properties of Mudstone. Rock Mechanics and Power Plants. Balkema, Rotterdam, 1, 133-144. 